\title{
STABILITY AND CONTROLLABILITY RESULTS OF EVOLUTION SYSTEM WITH IMPULSIVE CONDITION ON TIME SCALES
}

\author{
VIPIN KUMAR AND MUSLIM MALIK
}

\begin{abstract}
In this manuscript, we examine the Hyer's-Ulam stability and exact controllability results for impulsive evolution system on time scales. This manuscript has two segments: the first segment of the work is concerned with the Hyer's-Ulam type's stability analysis and the other segment is to exact controllability results. We used the Banach fixed point theorem, evolution operator theory and nonlinear functional analysis to establish these results. At last, we have presented some theoretical and numerical examples to outcome the utilization of these developed analytical results.
\end{abstract}

Mathematics subject classification (2010): 93B05, 34A37, 34N05, 37L05.

Keywords and phrases: Controllability, stability, time scales, evolution operator, impulsive systems.

\section{REFERENCES}

[1] V. Lakshmikantham, D. D. Bainov and P. S. Simeonov, Theory of impulsive differential equations, World scientific, 1989.

[2] M. Benchohra, J. Henderson and S. K. Ntouyas, Impulsive Differential Equations and Inclusions, Hindawi Publishing Corporation, New York, 2006.

[3] J. R. WANG, M. FEĈKAN AND Y. ZHOU, Ulam's type stability of impulsive ordinary differential equations, Journal of Mathematical Analysis and Applications, 395, (2012), 258-264.

[4] J. R. WANG AND X. LI, A uniform method to Ulam-Hyers stability for some linear fractional equations, Mediterranean Journal of Mathematics, 13, (2016), 625-635.

[5] Y. SHEN, The Ulam stability of first order linear dynamic equations on time scales, Results in Mathematics, 72, (2017), 1881-1895.

[6] S. ANDRS AND A. R. MszRos, Ulam-Hyers stability of dynamic equations on time scales via Picard operators, Applied Mathematics and Computation, 219, (2013), 4853-4864.

[7] S. HILGER, Ein Maßkettenkalkül mit Anwendung auf Zentrumsmannigfaltigkeiten, Ph.D. Thesis, Universität Würzburg, 1988 (in German).

[8] R. P. AgARWAL, C. WANG AND D. O'REGAN, Recent development of time scales and related topics on dynamic equations, Memoirs on Differential Equations and Mathematical Physics, 67, (2016), $131-135$.

[9] C. WANG, R. P. Agarwal And D. O'Regan, Compactness criteria and new impulsive functional dynamic equations on time scales, Advances in Difference Equations, 2016, (2016), 197.

[10] M. Bohner And A. Peterson, Dynamic Equations on Time Scales, An Introduction with Applications, Birkhauser, Basel, 2001.

[11] M. Bohner And A. Peterson, Advances in Dynamic Equations on Time Scales, Birkhauser, Boston, 2003.

[12] R. P. Agarwal and M. Bohner, Basic calculus on time scales and some of its applications, Results in Mathematics, 35, (1999), 3-22.

[13] V. KUmAR AND M. MaLiK, Existence and stability of fractional integro differential equation with non-instantaneous integrable impulses and periodic boundary condition on time scales, Journal of King Saud University - Science (2018), doi: https://doi .org/10.1016/j . jksus . 2018.10.011.

[14] S. Dhama AND S. ABBAS, Square mean almost automorphic solution of stochastic evolution equations with impulses on time scales, Differential Equations and Applications, 10(4), (2019), 449-469. 
[15] C. WANG AND R. P. AGARWAL, Weighted piecewise pseudo almost automorphic functions with applications to abstract impulsive nabla-dynamic equations on time scales, Advances in Difference Equations, 2014, (2014), 153.

[16] R. P. Agarwal, M. Bohner, D. O'Regan and A. Peterson, Dynamic equations on time scales: A survey, Journal of Computational and Applied Mathematics, 141, (2002), 1-26.

[17] V. KUMAR AND M. MALIK, Existence, uniqueness and stability of nonlinear implicit fractional dynamical equation with impulsive condition on time scales, Nonautonomous Dynamical Systems, 6(1), (2019), 65-80.

[18] S. S. Vadivoo, R. Ramachandran, J. CaO, H. Zhang And X. Li, Controllability analysis of nonlinear neutral-type fractional-order differential systems with state delay and impulsive effects, International Journal of Control, Automation and Systems, 16, (2018), 659-669.

[19] A. Debbouche And V. Antonov, Approximate controllability of semilinear Hilfer fractional differential inclusions with impulsive control inclusion conditions in Banach spaces, Chaos, Solitons and Fractals, 102, (2017), 140-148.

[20] M. Dieye, M. A. Diop AND K. EzZINBI, Controllability for some integrodifferential equations driven by vector measures, Mathematical Methods in the Applied Sciences, 40, (2017), 2090-2106.

[21] R. K. Goorge, D. N. Chalishajar and A. K. Nandakumaran, Controllability of second order semi-linear neutral functional differential inclusions in Banach spaces, Mediterranean Journal of Mathematics, 1(4), (2004), 463-477.

[22] V. LUPULESCU AND A. YOUNUS, On controllability and observability for a class of linear impulsive dynamic systems on time scales, Mathematical and Computer Modelling, 54, (2011), 1300-1310.

[23] M. J. Davis, I. A. Gravagne, B. J. Jackson, I. I. Marks and J. Robert, Controllability, observability, realizability and stability of dynamic linear systems, Electronic Journal of Differential Equations, 2009(37), (2009), 1-32.

[24] M. BOHNER AND N. WinTz, Controllability and observability of time-invariant linear dynamic systems, Mathematica Bohemica, 137(2), (2012), 149-163.

[25] C. Duque, J. Uzcategui and H. Leiva, Controllability of semilinear dynamic systems on time scales, Journal of Abstract Differential Equations and Applications 82, (2017), 70-80.

[26] M. MALIK AND V. KUMAR, Controllability of neutral differential equation with impulses on time scales, Differential equations and Dynamical Equations, (2019), doi.org/10.1007/s12591-019-00454-2.

[27] M. MALIK AND V. KUMAR, Existence, stability and controllability results of a Volterra integrodynamic system with non-instantaneous impulses on time scales, IMA Journal of Mathematical Control and Information, (2011), dnz001, doi.org/10.1093/imamci/dnz001.

[28] V. LupulesCu AND A. Younus, Controllability and observability for a class of time-varying impulsive systems on time scales, Electronic Journal of Qualitative Theory of Differential Equations 95, (2011), 1-30.

[29] V. Kumar AND M. Malik, Controllability results for a Volterra integro dynamic inclusion with impulsive condition on time scales, To appear in Rocky Mountain Journal of Mathematics, Math. https://projecteuclid.org/euclid.rmjm/1563847346. 